\title{
ONYCHIA DUE TO BACILLUS COLI COMMUNIS
}

LESTER HOLLANDER, M.D.

PITTSBURGH

Two cases of onychia have come under my observation within the last twelve months in which cultures from the purulent material obtained from the nail bed yielded practically a pure strain of Bacillus coli communis.

\section{REPORT OF CASES}

Cas: 1.-History-Mrs. A. J. H., aged 52, was referred to me on account of a chronic onychitis affecting three nails on the right hand and one nail on the left, of about five months' standing. The patient did not remember definitely any injury to the nails or to the nail told. The first symptom which attracted her attention was a severe burning sensation in two of the fingers at the nail bed. She did not notice any change in color, nor was there any visible swelling at this time. The burning sensation had increased from time to time until about three weeks after the onset, when the nail fold over the nail bed became red and considerably swollen. On the advice of a physician, the patient applied hot fomentations of boric acid solution, but did not experience any relief. The burning sensation was supplemented by considerable pain and throbbing, especially at night. In the morning she could press out a little pus from the nail fold and obtain some relief. Within another month, another nail bed on the right and one on the left hand became involved.

Examination.-The distal phalanges of ali the involved fingers were swollen and red. On pressure over the nail bed a purulent material was obtained. The nail wall was inflamed and the involved nails were thickened, uneven, and considerably loosened from the nail wall.

Culture from the expressed pus yielded $B$. coli communis.

Treatment.-The nail bed was incised along the margin of the nail wall, and compresses of the following solution were applied continuously for one week, and only at night for another week, with complete recovery.

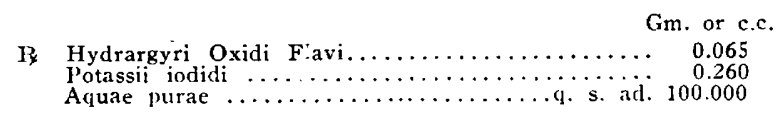

CASE 2.-History.-Mrs. I. S., aged 40, was referred to me on account of a similar complaint. Both thumbs and all the fingers were involved in a chronic onychitis. The distal phalanges were markedly swollen, and the nails were rough, uneven, very brittle, and of a dark brownish, dirty color. The trouble was of a year's standing and very annoying, not only from a cosmetic standpoint, but also because it interfered with the patient's housework, because of the extreme sensitiveness experienced, following the use of her hands. She could not remember any injury from manicuring, or other type of trauma to her fingers. The patient was very emphatic in the statement that she began 
to experience a burning sensation in all her finger tips at about the same time and that the visible changes in the nail folds appeared almost simultaneously within a few days after the annoying sensation developed.

Examination.-After incising the nail beds, the pus was separately cultivated and the offending organism in all the cultures proved to be $B$. coli contmunis.

Treatment.-This patient complained of frequent headaches, marked constipation, and of a constant languid feeling.

The treatment used in Case 1 failed to effect a permanent cure. So, after several surgical drainings, an autogenous vaccine was made and administered.

This produced a marked change not only in the onychitis, but also in the general condition, including the constipation.

\section{COM MENT}

These two cases permit the assumption of two different routes of conveyance of the infecting organism. The first case, presenting no general symptomatology and a rapid relief after surgical interference, may have been a contact infection, while the second case, an autogenous one, through the hemotogenous route.

7133 Jenkins Arcade Building. 